\title{
分析用諸溶液の保存に就て （次亞鹽素酸曹達標準液，モリフテン゙酸アムモニウム試藥，可溶性澱粉指示藥）
}

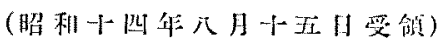

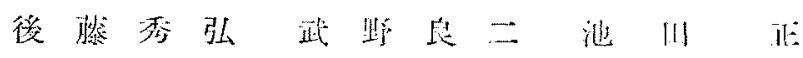

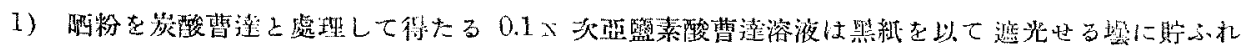

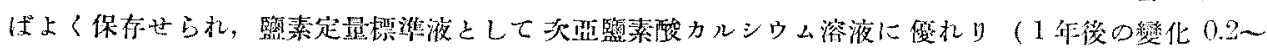
$0.7 \%)$ ，但炭酸曹洼の大過剩は之を塠くぶし.

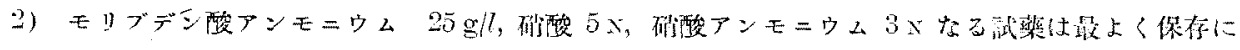

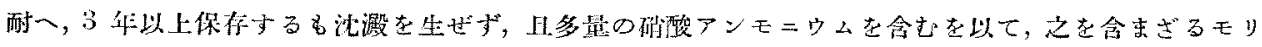

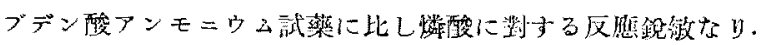

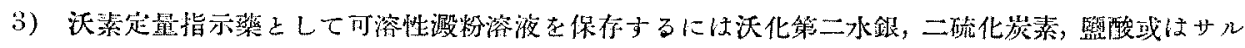
チル酸の少量老添加すべし.斯くして保存せるものは10ケ月以上にわたりて沃素反照に變化在些せ

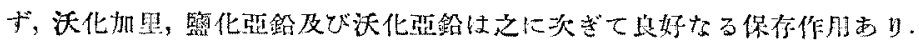

\section{I. 次亞鹽素酸曹達標準液}

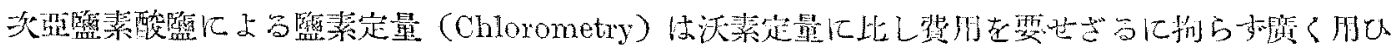

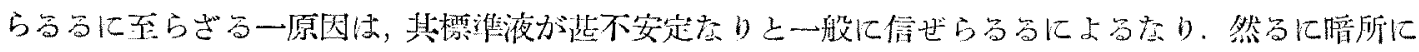

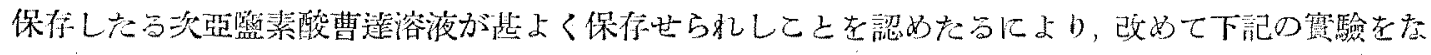

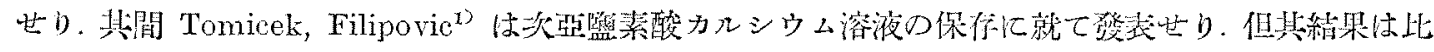

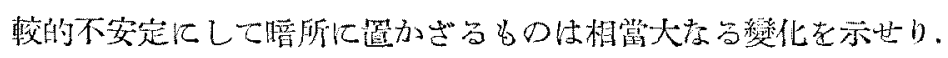

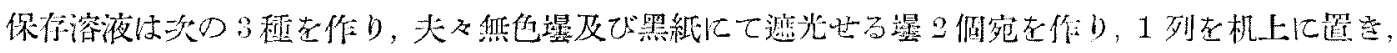
他の 1 列を机中(暗所)に通くこととせり。

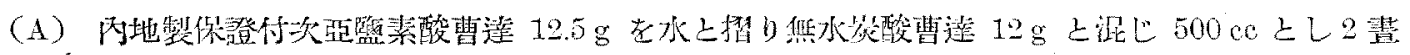

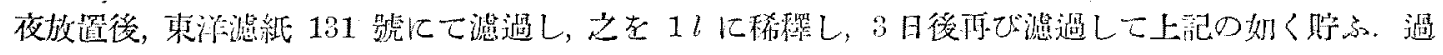

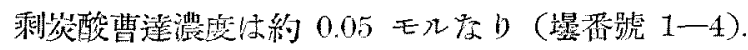

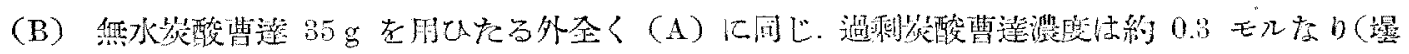
番䟽 5-8).

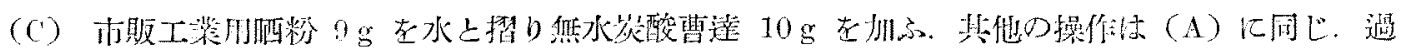

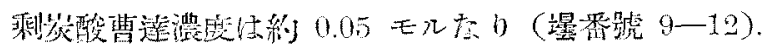

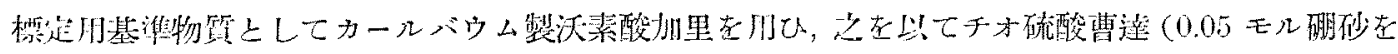

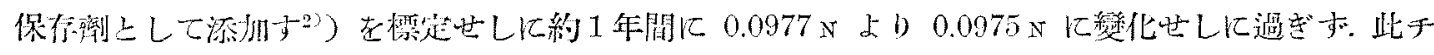

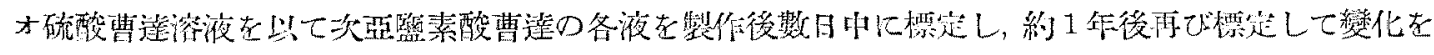

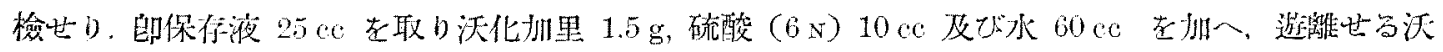

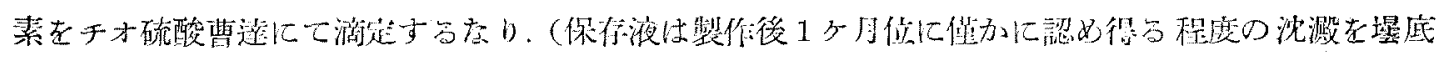

1) Collertion, 10(1938), 340 .

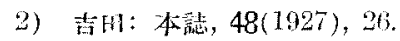




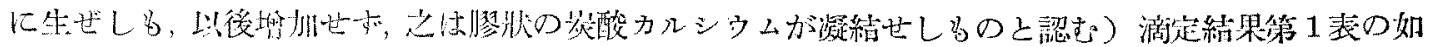
L.

\begin{tabular}{|c|c|c|c|c|c|c|c|c|c|}
\hline \multirow{2}{*}{ 乘跕 } & \multirow{2}{*}{18} & \multirow[b]{2}{*}{ 保保堵所 } & \multirow{2}{*}{ 涳㖡程数 } & \multicolumn{2}{|c|}{$\mathrm{Na}_{\mathrm{A}} \mathrm{SO}_{3}$ 游是量 $\mathrm{ec}$} & \multicolumn{2}{|c|}{ 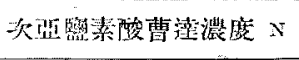 } & \multicolumn{2}{|c|}{ 變化程度(355日後) } \\
\hline & & & & $\begin{array}{l}\text { 初 } \\
\left(0.00-\frac{1}{1}\right)\end{array}$ & $\begin{array}{c}30501 \text { 㷋 } \\
(0.0070 \mathrm{x})\end{array}$ & 伎 初 & $355 日$ 媵 & $\mathrm{v}$ & $\%$ \\
\hline 1 & \multirow{6}{*}{ 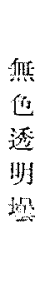 } & \multirow{3}{*}{ 机上 } & $A$ & 27.44 & 27.30 & 0.1073 & 0.1064 & 0.0000 & 0.84 \\
\hline 5 & & & $\mathrm{~B}$ & 27.60 & 20.88 & 0.1070 & 0.1046 & 0.0033 & 3.06 \\
\hline 9 & & & c: & 23.05 & 20.77 & $(0.0,0) 1$ & 0.0888 & 0.0013 & 1.44 \\
\hline 3 & & \multirow{3}{*}{ 暗所 } & 1 & $\$ 6.85$ & $\because 6.8$ & $0.10=0$ & 0.1046 & 0.0004 & 0.34 \\
\hline $\bar{T}$ & & & 13 & 27.85 & 27.73 & $\left.0.108^{\prime}\right)$ & 0.1081 & 0.0005 & 0.73 \\
\hline $1 I$ & & & $c^{\prime}$ & 23.40 & 23.31 & 0.0215 & 0.0003 & 0.0001 & 0.65 \\
\hline$\because$ & \multirow{3}{*}{ 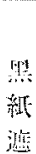 } & \multirow{3}{*}{ 机上 } & $A$ & 27.62 & 27.64 & 0.1080 & 0.1078 & 0.0002 & 0.19 \\
\hline $1 i$ & & & $\mathrm{~B}$ & $\because 7.17$ & $\because t .11$ & 0.1062 & 0.1057 & 0.0005 & 0.47 \\
\hline 10 & & & C & 32.65 & 22.08 & 0.0886 & 0.0880 & 0.0006 & 0.67 \\
\hline 4 & \multirow{3}{*}{$\begin{array}{l}* \\
y\end{array}$} & \multirow{3}{*}{ 峭所 } & $A$ & $2 \pi .67$ & $=7.60$ & 0.1082 & 0.1078 & 0.0001 & 0.37 \\
\hline 8 & & & $\mathrm{~B}$ & -7.58 & 27.52 & 0.1078 & 0.1073 & 0.0005 & 0.46 \\
\hline 12 & & & $C^{\prime}$ & .29 .86 & 2.83 & 0.0894 & 0.0829 & 0.0004 & 0.45 \\
\hline
\end{tabular}

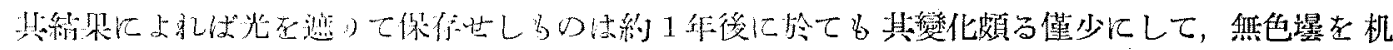

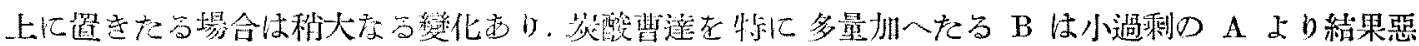
く，不純品 C は純品 A 上少しく劣る批向在示せり．

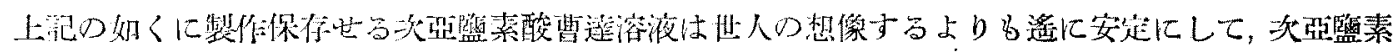
酸カルシウム浚液

\section{II. モリブデン酸アムモニウム試藥}

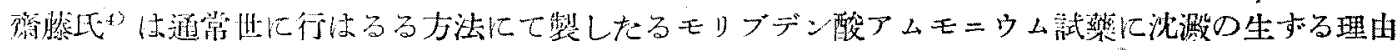

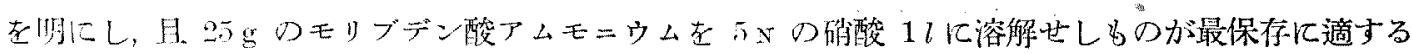

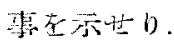

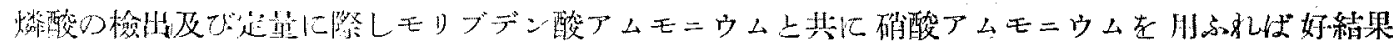

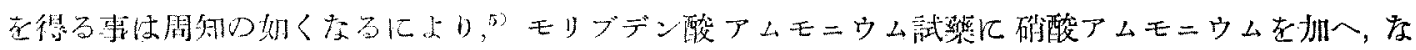

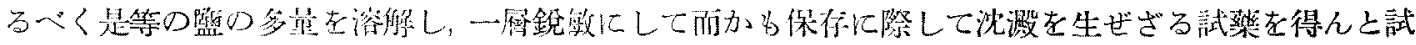

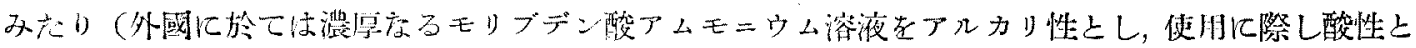

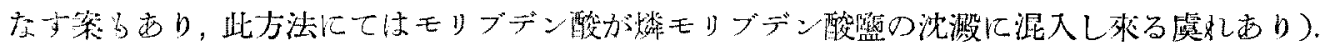

モリブデン酸アンモニウム（メルク慗分析月） $5 ， 4.5,4,3.5,3,2.5 \mathrm{~g} / 100 \mathrm{cc}$; 硝酸(同上) $5,4,3 \mathrm{~N}$;

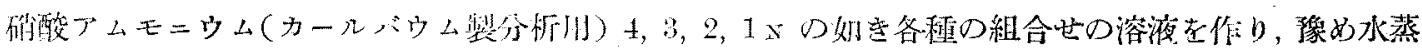

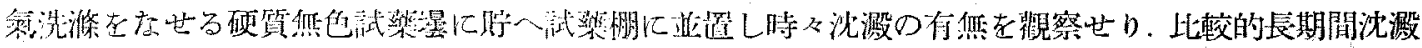

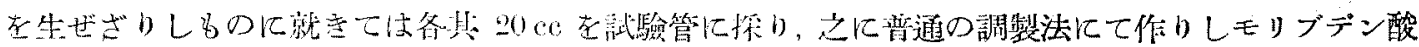

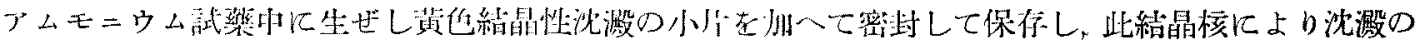

3) Kolthoff, Stenger: Ind. Eng. Chem. Analyt Fl., 7(1935), 79. 4) 柆䞏, 47(1926), 115. 


\begin{tabular}{|c|c|c|c|c|c|c|}
\hline \multirow{3}{*}{ 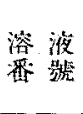 } & \multirow{3}{*}{ 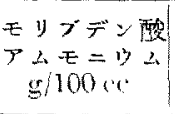 } & \multirow{3}{*}{ 㮐酒参 } & \multirow{3}{*}{ 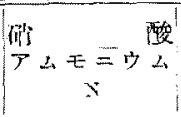 } & \multirow{2}{*}{\multicolumn{2}{|c|}{ 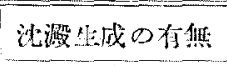 }} & \multirow{3}{*}{ 接㮔法口絬果 } \\
\hline & & & & & & \\
\hline & & & & 1 年後 & 3 科得 & \\
\hline 1 & 5 & $\bar{y}$ & 4 & + & + & \\
\hline$\ddot{z}$ & $"$ & $"$ & 3 & + & + & \\
\hline 3 & " & $"$ & 2 & + & + & \\
\hline 4 & " & $"$ & 1 & + & + & \\
\hline$\overline{3}$ & " & 4 & 4 & + & + & \\
\hline i) & " & $"$ & 3 & + & + & \\
\hline $\bar{i}$ & " & " & 2 & + & + & \\
\hline 8 & " & $"$ & 1 & + & + & \\
\hline 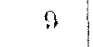 & $"$ & 3 & 4 & + & + & \\
\hline 10 & " & $"$ & 3 & + & + & \\
\hline 11 & " & $"$ & 2 & + & + & \\
\hline 12 & " & $"$ & 1 & + & + & \\
\hline 13 & 4.5 & 5 & 2 & + & + & \\
\hline 14 & "' & $"$ & 1 & + & + & \\
\hline 15 & $"$ & 4 & 1 & + & + & \\
\hline 16 & 4 & 5 & 2 & + & + & \\
\hline 17 & $"$ & $" \prime$ & 1 & + & + & \\
\hline 18 & " & 4 & 1 & + & + & \\
\hline 19 & 3.5 & 5 & 2 & - & - & \\
\hline 20 & $"$ & $"$ & 1 & - & - & \\
\hline 21 & $"$ & 4 & 1 & - & - & \\
\hline 22 & 3 & 5 & 4 & + & + & \\
\hline 23 & $"$ & $"$ & 3 & + & + & \\
\hline 24 & $"$ & $"$ & 2 & - & + & 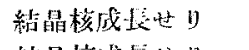 \\
\hline 25 & $"$ & $"$ & 1 & - & - & 結晶核成长坶 y \\
\hline 26 & $"$ & 4 & 4 & + & + & \\
\hline 27 & $"$ & $"$ & 3 & + & + & \\
\hline 28 & " & $"$ & 2 & + & + & \\
\hline 29 & $"$ & $"$ & 1 & - & - & 絬晶核成烓せり \\
\hline 30 & " & 3 & 4 & + & + & \\
\hline 31 & $"$ & $"$ & 3 & + & + & \\
\hline 32 & " & $"$ & 2 & + & + & \\
\hline 33 & " & $"$ & 1 & + & + & \\
\hline 34 & 2.5 & 5 & 4 & + & + & \\
\hline 35 & " & $" \prime$ & 3 & - & - & 絬晶核溶的やり \\
\hline 36 & " & " & 2 & - & - & 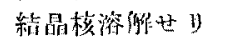 \\
\hline 37 & $"$ & $"$ & 1 & - & - & 絬昆核溶把せり \\
\hline 38 & $"$ & 4 & 4 & + & + & \\
\hline 39 & $"$ & $"$ & 3 & + & + & \\
\hline 40 & $"$ & " & 2 & - & - & 結品核殆溶你拉り \\
\hline 41 & $"$ & $"$ & 1 & - & - & 結品核成辰忖げ \\
\hline 42 & " & 3 & 4 & + & + & \\
\hline 43 & $"$ & $"$ & 3 & + & + & \\
\hline 44 & " & " & 2 & + & + & \\
\hline 45 & $"$ & $"$ & 1 & - & - & 絬品核成辰せ y \\
\hline
\end{tabular}

生成が促進些斿当や走 檢せり (是等の溶液は

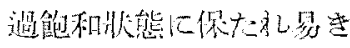

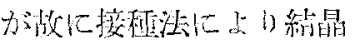

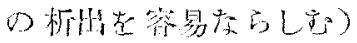

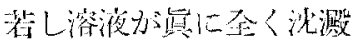

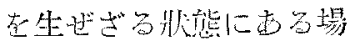

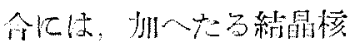

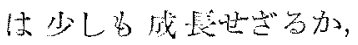
丈は反つて缩解し上る心

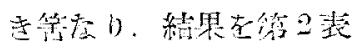
に示可。

其闪很35,86,87,40,41

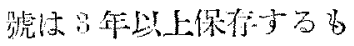

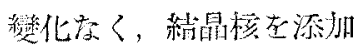

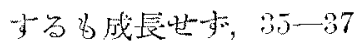
敌にては反つて溶等せ b. 依て确酸つムモニウ 么老摱多量に念们世る35 號老保持上最良の为の上 沈定辂り。

(符 10, 20,21 跟は緹 晶核然嚗中にて留だ く保侍出ら悓た礼ざ，夫 そ是等に相賞して且もり ブデン酸アムモニウムの 舍量低符 24，25，年栫 が皆接程法にて絬暃の成

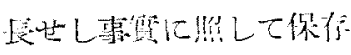

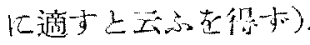

\section{III. 可溶性澱粉指 示薬}

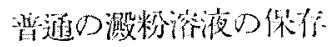
に就ては蚬に和上的の磁 公市b。

カールパウム型可塎性 潵粉 $6 \mathrm{~g}$ 老 $30 \mathrm{cc}$ ○水上

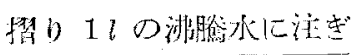

6) 本誌，42(1921), 974. 


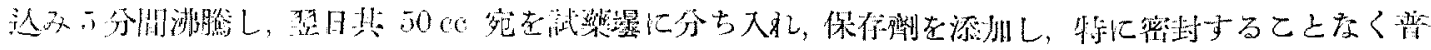

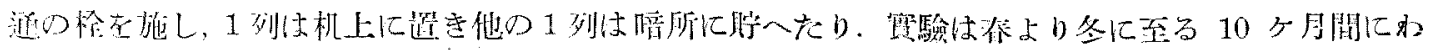

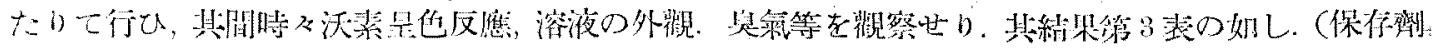

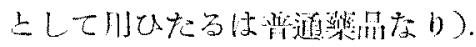

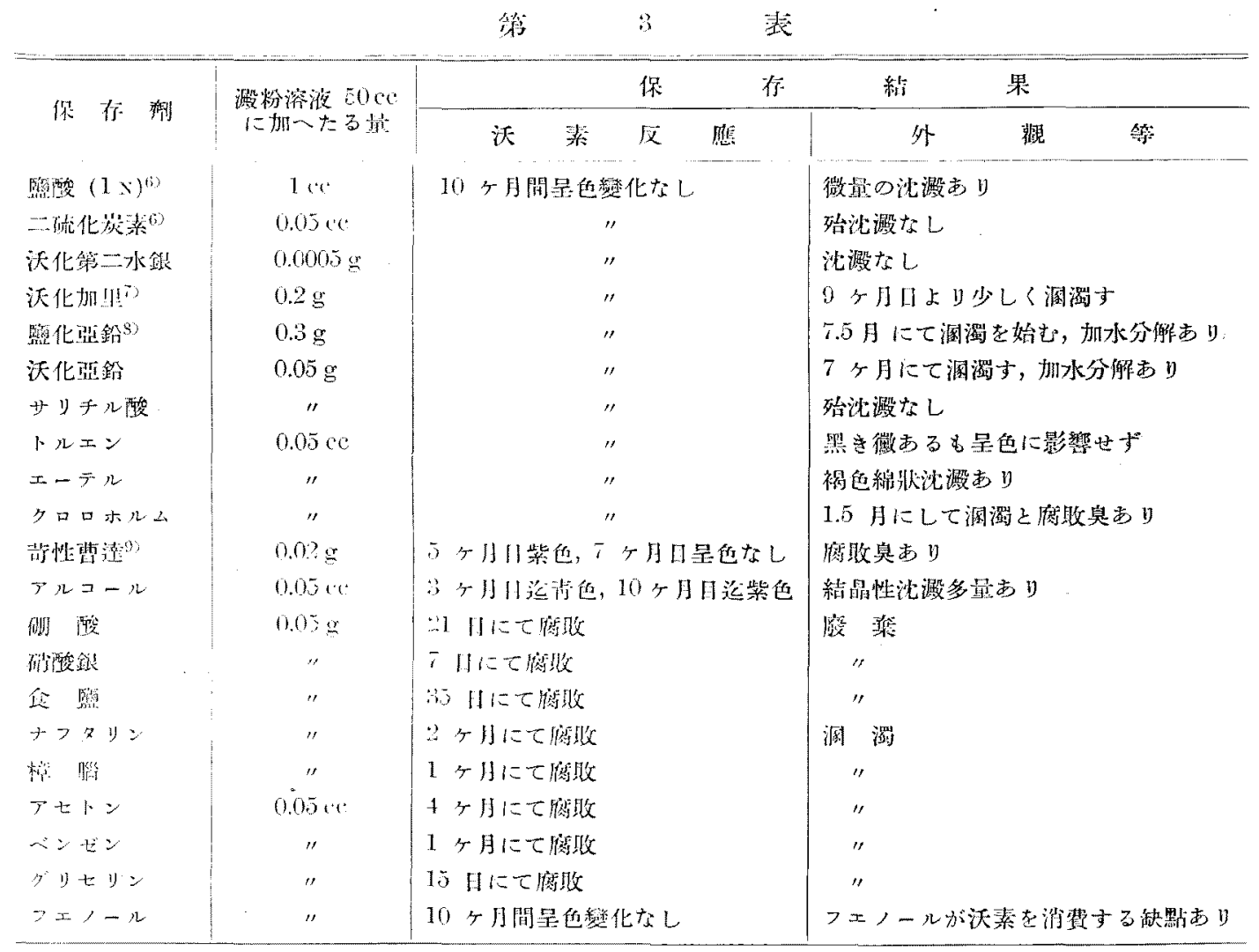

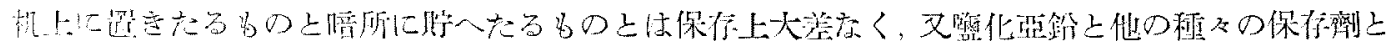

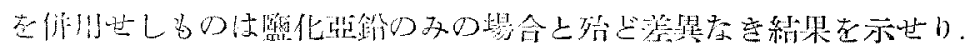

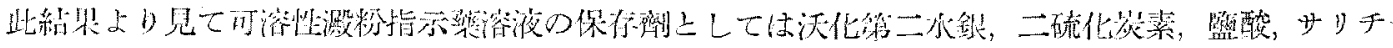

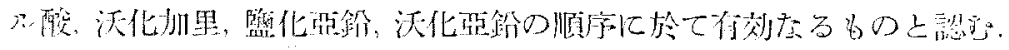

小怀教授に對して本砄究の指導を感謝与。

(束北河阈大學理學部化學数宝)

7) Trealwell, Hall: "Analytical Chemistry" 8. Ed ,.597.

8) Ibił., 7. Ed,, 557.

9) Scott: "Standard Metherls of Chenical Analysis" 4. Ed., 241. 